\title{
PHOTOLYSIS OF THE AZIDE ION IN AQUEOUS SOLUTION
}

\author{
K. TENNAKONE*, O. A. ILLEPERUMA**, S. PUNCHIHEWA, \\ A. C. JAYASURIYA \\ Institute of Fundamental Studies, Hantana Road, Kandy, Sri Lanka.
}

\section{AND}

\author{
A. H. JAYATISSA \\ Department of Physics, University of Rubuna, Matara, Sri Lanka.
}

(Date of receipt : 21 December 1988)

(Date of acceptance : 31 January 1989)

\begin{abstract}
The photolysis of the azide ion in an aqueous medium purged with argon is found to generate ammonia and nitrogen whereas oxygen purged solutions generate nitrite and nitrogen. Quantum yield measurements are given and possible reaction mechanisms are suggested.
\end{abstract}

\section{Introduction}

The kinetics of the decomposition of inorganic azides in solid state have received considerable attention. ${ }^{4,7,9}$ In vacuum all azides decompose into metal and nitrogen, the decomposition can be brought about by heat, light, shock or ionizing radiation. Heavy metal azides in solid state show absorption edges in the vicinity of $300-400 \mathrm{~nm}$. The photochemical decomposition of heavy metal azides is believed to originate from band gap excitations which generate electron-hole pairs. ${ }^{9}$ However, in the case of alkaline metal azides the excitonic absorption in the region $140-150 \mathrm{~nm}$ is known to cause the decomposition. ${ }^{9}$ According to Beckman and Dikinson, ${ }^{1}$. the photolysis of hydrogen azide solution yields gaseous nitrogen, ammonia, hydrazine and hydroxylamine. Nosaka et al.,6 have reported that photolysis of azide ion (aqueous medium) in the presence of semiconductor catalysts produce ammonia and nitrogen. However, they have not compared the yields in the absence and presence of semiconductor catalysts. We have carefully examined the photolysis of azide ion in the presence and absence of semiconductor catalysts and found that the photodecomposition of azide ion in aqueous medium is not influenced by semiconductor catalysts.: The only detectable products in the photolysis of argon purged solutions were ammonia and nitrogen. Photolysis of oxygen purged solutions yielded nitrite ion and nitrogen.

\section{Experimental Method}

Photolysis experiments were carried out in a double walled photochemical reactor (Applied Photophysics) made from borosilicate glass. The central

*Department of Physics, University of Rubuna, Matara, Sri Lanka.

**Department of Chemistry, University of Peradeniya, Sri Lanka. 
axis of the cylinder is fitted with a $400 \mathrm{~W}$ medium pressure $\mathrm{Hg}$ lamp. A facility is also provided for the insertion of cylindrical glass filters. $350 \mathrm{ml}$ of sodium azide solution was continuously irradiated and aliquots of solution drawn at different intervals of time were tested for ammonia (indophenol blue $\operatorname{method}^{3}$ ) hydrazine ( $\mathrm{p}$-dimethylaminobenzaldehyde $\operatorname{method}^{8}$ ) and hydroxylamine (potassium iodate resorcinal reagent ${ }^{2}$ ). All these estimations were carried out spectrophotometrically. Before irradiation, solution was rapidly purged with purified argon. The gas in the atmosphere of the reactor and in the solution was analysed for nitrogen, oxygen and hydrogen by gas chromatography (Shimadzu model E6-9AM). An International light IL 700 radiometer was used for the measurement of light intensities. The absorption spectrum of the azide solution was recorded using a Shimadzu UV3000 spectrophotometer.

\section{Results and Discussion}

In argon purged solutions the only detectable products of photolysis were ammonia and nitrogen (hydrazine and hydroxylamine were absent or less than $10^{-6} \mathrm{M}$ ). Figure 1 indicates the yield of ammonia as a function of time. The absorption spectrum of the sodium azide solution shows a sharp edge (Figure 2) at $\sim 280 \mathrm{~nm}$. Photodecomposition is seen to occur only if the irradiation wavelength is $\lesssim 280 \mathrm{~nm}$ (when a filter that cuts off light of wavelength $\sim 300 \mathrm{~nm}$ was used, the decomposition did not take place). The quantum yields of ammonia and nitrogen at $\lambda=265 \mathrm{~nm}$ (the significant emission in the lamp at $\lambda<300 \mathrm{~nm}$ is $265 \mathrm{~nm}$ and the intensity at this wavelength estimated using a monochromator is $\bumpeq 4.9 \mathrm{X}^{10^{16}}$ photons $\mathrm{s}^{-1}$ ) was estimated to be $5.3,18.6 \%$ respectively. 


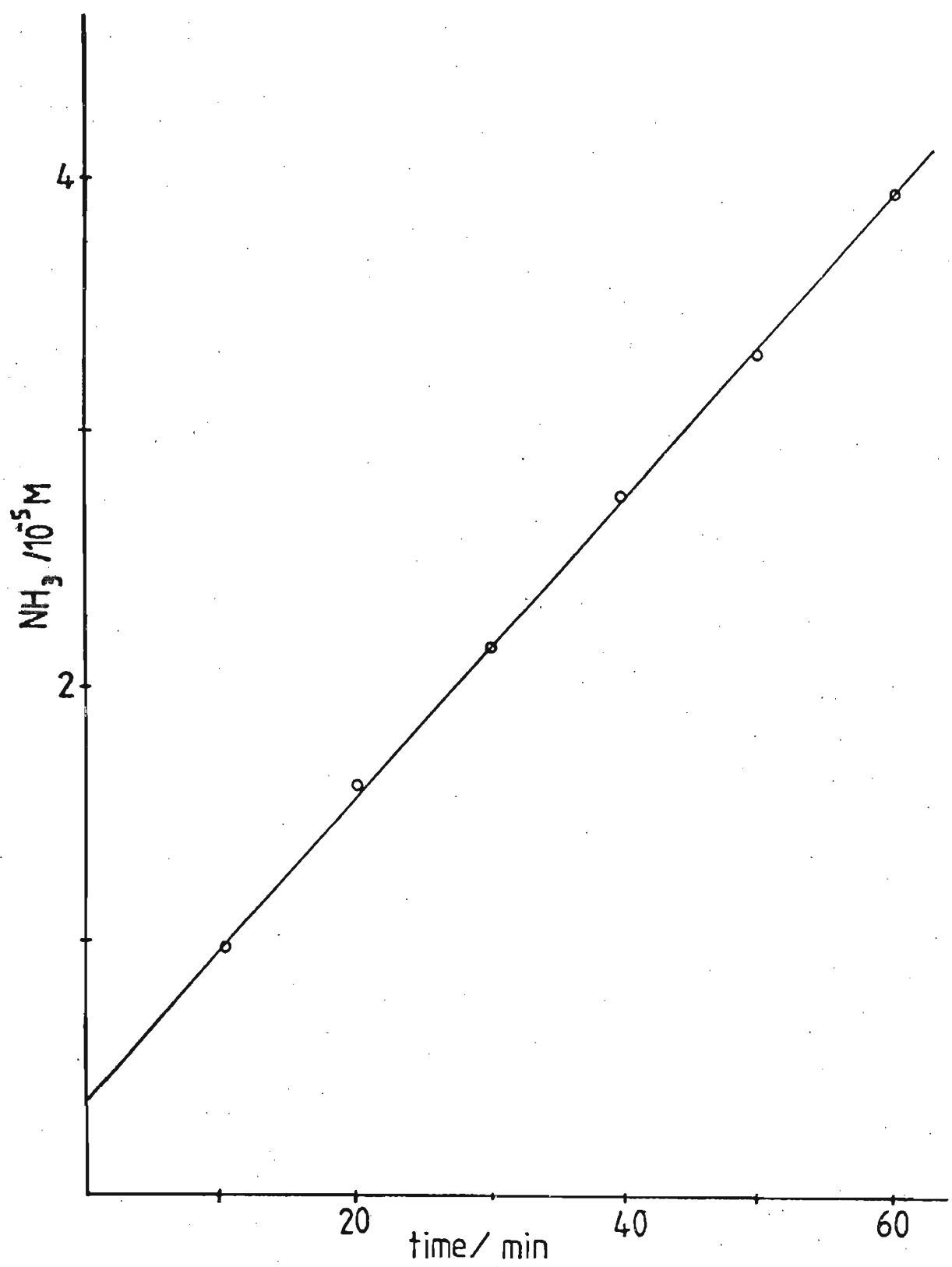

Figure 1. Time variation of the ammonia yield in an argon purged solution (Initial concentration azide $2.2 \times 10^{-4} \mathrm{M}$ ) 


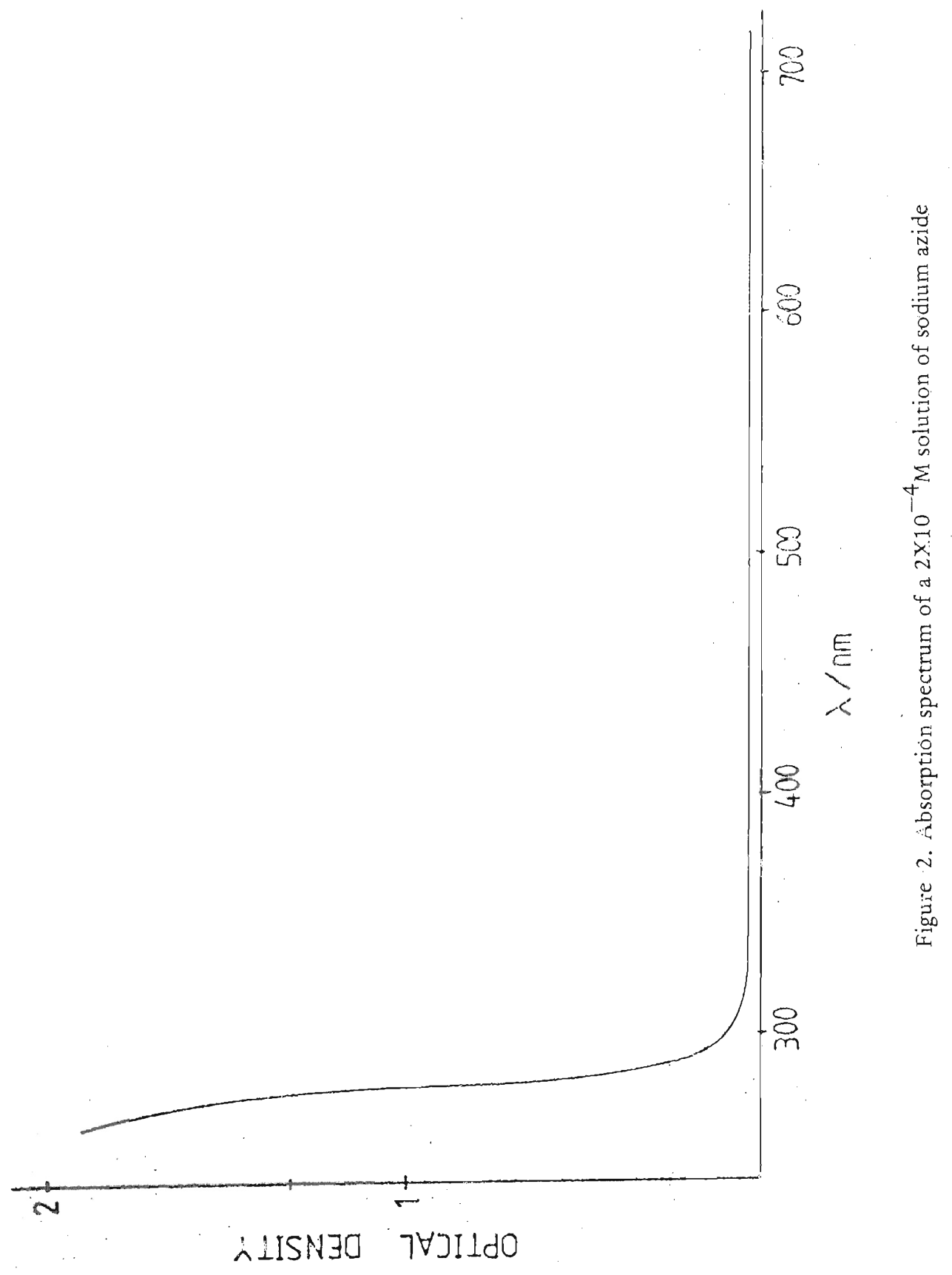




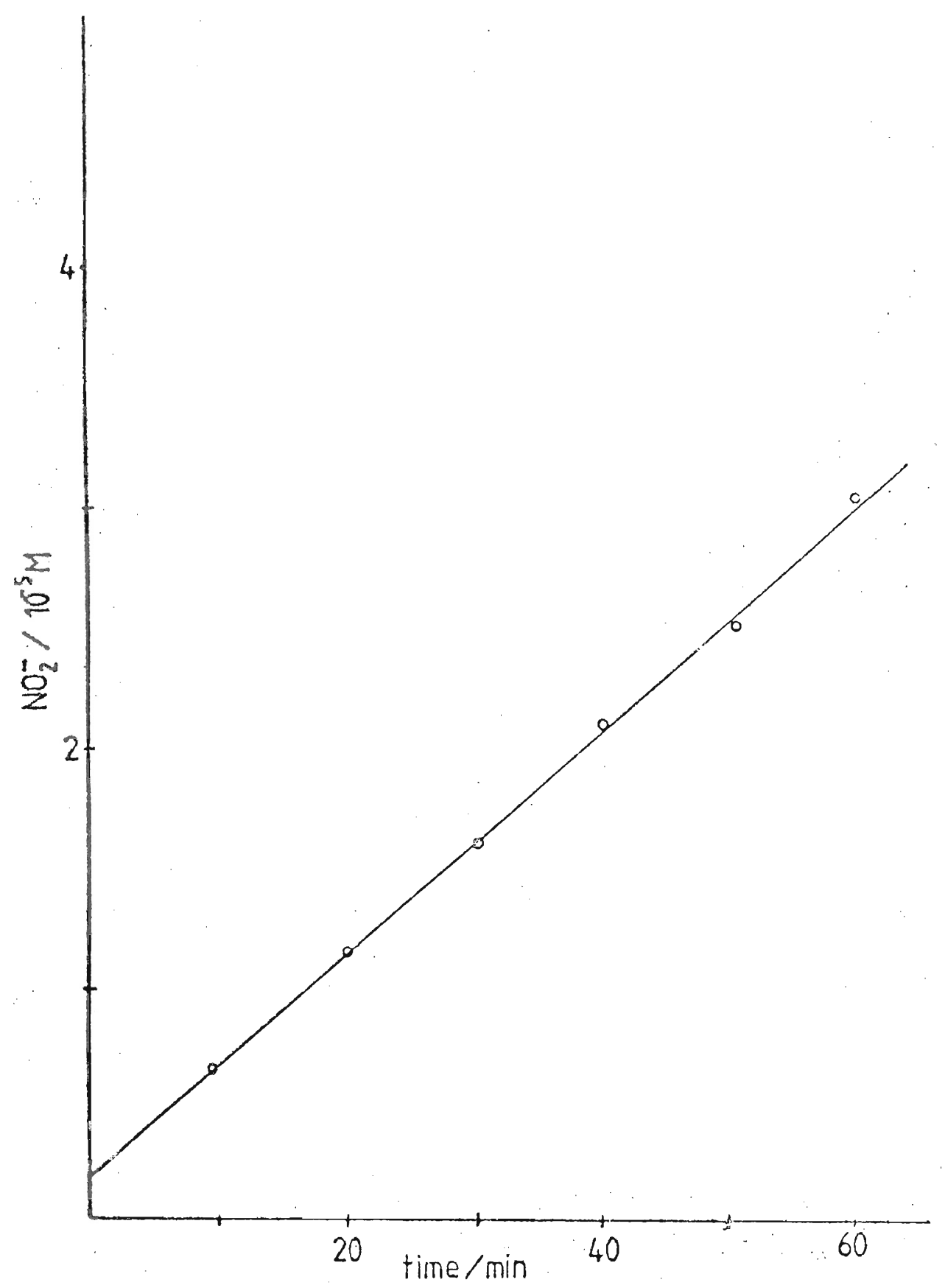

Figure 3. Time variation of the nitrite yield in an oxygen purged solution (Initial concentration of azide $=2.2 \times 10^{-4} \mathrm{M}$ ) 
When the solution was purged with $\mathrm{O}_{2}\left(160 \mathrm{ml} \mathrm{min}^{-1}\right)$ the products of photolysis were nitrite and nitrogen with barely detectable amounts of ammonia. The quantum yields of nitrite, nitrogen were found to be 41 , $4.7 \%$ respectively. Semiconductor photocatalysts did not have any influence on yields or the products of photolysis. Again, in both cases (ammonia production in argon purged solution and nitrite production in oxygen purged solution) were found to be insensitive to changes in $\mathrm{pH}$. The photochemical reactions occurring can be summarized as follows:

$$
\begin{aligned}
& 3 \mathrm{~N}_{3}^{-}+3 \mathrm{H}_{2} \mathrm{O}-\stackrel{\mathrm{h} \nu}{\mathrm{NH}_{3}+4 \mathrm{~N}_{2}+3 \mathrm{OH}^{-}} \\
& \mathrm{N}_{3}^{-}+\mathrm{O}_{2}-\mathrm{hv} \mathrm{NO}_{2}^{-}+\mathrm{N}_{2}
\end{aligned}
$$

The observed ratios of the quantum yields $\left(\mathrm{NH}_{3}: \mathrm{N}_{2} \sim 1: 3.5, \mathrm{NO}_{2}{ }^{-}\right.$: $\mathrm{N}_{2} \sim 1: 1.1$ ) agrees with (1) and (2). The insensitivity of the reaction to $\mathrm{pH}$ and the presence of semiconductor catalysts suggests that the primary step in photolysis does not involve charge transfer from azide to $\mathrm{H}^{+}$ions, but instead the excited azide ion or an intermediate product of its decomposition directly interacts with water molecules or oxygen.

\section{Acknowledgement}

One of the authors (A. H. J.) is supported by a grant RG/86/P2 from the Natural Resources, Energy and Science Authority of Sri Lanka.

\section{References}

1. BECKMANN, A. O. \& DIKINSON, R. G. (1930) J. Am. Chem. Soc. 52:129

2. GOBERTT, H. (19.34) Biochem. J. $28: 1575$.

3. GRAYER, S. \& HALMAN, M. (1984).J. Elcetroanal. Chem. $170: 363$.

+. JACOBS, P. W. M., TOMKINS, F. C. \& PAI-VERNKER, V. R. (1962) J. Pbys. Chem. 66 : 1113.

5. NOSAKA, Y., ISHIZUKA, Y., NORIMATSU, K. \& MIYAMA, II. (1984) Bull. Chem. Soc. Jpn. $57: 3066$.

6. NOSAKA, Y., NORIMATSU, K. \& MIYAMA, H. (1984) Chem. pbys, Lett. $106: 128$.

7. REITZNER, B., KANFMAN, J. V: R.\& BARTELL, E. F. (1962) J. Pbys. Chem. $66: 421$.

8. WATT, G. W. \& CHRISP, J. D: (1952) Anal. Chem. $24: 2006$.

9. YOFFE, A. D. (1966) The Inorganic Azides in Developments in inorganic nitrogen chemistry, edited by C. B. Colburn, Elsevier, Amsterdam, p. 73. 